\title{
KEDUDUKAN DPD RI DALAM SISTEM TATA NEGARA PERSPEKTIF SIYASAH
}

\author{
SITI NURKHADIJAH \& ZUL ANWAR AJIM HARAHAP \\ IAIN Padangsidimpuan
}

\begin{abstract}
The discussion of this paper is motivated by the contradiction of functions, roles and competencies of the DPD RI. The purpose of this research was to find out the position of the DPD in the Indonesian state system and to find out the views of the siyasa fiqh on the position of the DPD in the Indonesian constitutional system. The results of this research indicated that the position of the DPD RI in the Indonesian state system has limited position and authority. The position and competence of the RI DPD should be strengthened so that the performance of a DPD RI institution becomes better in regional autonomy. If the DPD RI has an unlimited position, it gives a special authority in building the region. The view of siyasa fiqh towards the position of the Republic of Indonesia Regional Representative Council in the Indonesian state system is inconsistent and inappropriate, because Ahlul al-Halli wa al-'Aqdi is a representative of the people who can give fatwa, while the DPD RI is an institution that has the authority limited.
\end{abstract}

Keywoards : DPR RI, Indonesian Constitutional System, Siyasah

\begin{abstract}
Abstrak
Pembahasan tulisan ini dilatarbelakangi oleh adanya bertolak belakang dari fungsi dan peran serta kompetensi DPD RI. Tujuan penelitian ini adalah untuk mengetahui Kedudukan DPD RI dalam sistem tata negara Indonesia dan untuk mengetahui pandangan fiqih siyasah terhadap kedudukan DPD dalam sistem ketatanegaraan Indonesia. Hasil dari penelitian ini menunjukkan bahwa kedudukan lembaga DPD RI dalam sistem tata negara Indonesia mempunyai kedudukan dan kewenangan yang terbatas. Seharusnya kedudukan dan kompetensi DPD RI itu harus diperkuatkan agar kinerja suatu lembaga DPD RI menjadi lebih baik dalam otonomi daerah. Jika DPD RI mempunyai kedudukan tidak terbatas, maka ia mempunyai kewenangan khusus dalam membangun daerah. Pandangan fiqih siyasah terhadap kedudukan DPD RI dalam sistem tata negara Indonesia yang ada selama ini tidak sejalan dan tidak sesuai, karena Ahlul al-Halli wa al-'Aqdi merupakan perwakilan
\end{abstract}


226 | TAZKIR: Jurnal Penelitian Ilmu-ilmu Sosial dan Keislaman

Vol. 03 No. 2 Desember 2017

rakyat yang dapat memberi fatwa, sedangkan DPD RI merupakan lembaga yang mempunyai kedudukan kewenangan yang terbatas.

Kata Kunci : DPR RI, Tata Negara, Siyasah

\section{PENDAHULUAN}

\section{LATAR BELAKANG MASALAH}

Pada permulaan lahirnya negara Islam, pembagian kekuasaan negara belum tampak, karena Al-Qur'an dan Sunnah Rasul tidak memberikan konsepsi secara terperinci, tetapi hanya bersifat global semata. Nabi Muhammad Saw, bukan hanya sebagai Rasul yang membawa risalah Islamiyah, melainkan pula sebagai kepala negara merangkap sebagai hakim yang mengadili setiap perkara.

Kendati pun nabi pada masa itu merangkap berbagai jabatan, namun sudah terlihat adanya isyarat yang menunjukkan bahwa pada saat tertentu, beliau mengangkat para pembantunya di daerah-daerah tertentu untuk bertindak sebagai penguasa dan qadhi.

Setelah Rasulullah Saw. Wafat, tugas "kekhalifahan digantikan oleh sahabat Abu Bakar dan pada masa itu urusan qadha diserahkan kepada Umar bin Khattab 2 tahun lamanya" begitu pula setelah kekuasaan dipegang Umar bin Khattab, ia memisahkan antara kekuasaan peradilan dan kekuasaan pemerintahan, dan ia mengangkat Abu Darda sebagai qadhi kota Madinah, dan Syurekh bin Qaes bin Abi al Ash di Mesir.

Konsep Kepemimpinan Menurut Alqur'an pada dasarnya secara tersirat menyebutkan kata kepemimpin (leadership) merupakan istilah dalam manajemen organisasi. Sebutan pemimpin muncul ketika seorang memiliki kemampuan mengetahui dan mampu mengarahkan perilaku orang lain, mempunyai kepribadian khas, dan mempunyai kecakapan tertentu yang tidak dimiliki semua orang. Di bidang pemerintahan atau negara, pemimpin disebut dengan berbagai nama, misalnya, imamah (dikalangan Shi'i) dan khalifah (dalam tradisi Sunni), raja untuk kerajaan atau presiden dalam istilah negara republik.

Kekuasaan ketatanegaraan Islam, berada di tangan umat, ahl alhalliwa al-'aqd bisa dianggap mewakili umat dalam menentukan siapa penguasa yang akan memimpin umat, dalam menentukan siapa penguasa yang akan memimpin umat, khususnya dalam melaksanakan fardhu 
kifayah dalam pengangkatan khalifah, yang tidak harus dilakukan oleh semua umat. Adapun dalil yang dapat digunakan mengenai kedudukan ahl al-halli wa al-'aqd sebagai berikut:

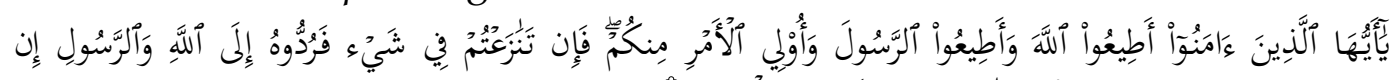

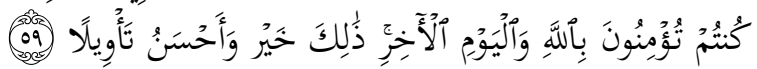

Artinya: Hai orang-orang yang beriman, taatilah Allah dan taatilah Rasul (Nya), dan ulil amri di antara kamu. kemudian jika kamu berlainan Pendapat tentang sesuatu, Maka kembalikanlah ia kepada Allah (Al Quran) dan Rasul (sunnahnya), jika kamu benar-benar beriman kepada Allah dan hari kemudian. yang demikian itu lebih utama (bagimu) dan lebih baik akibatnya. (surah Annisa ayat 59).

Berdasarkan ayat ini dapat dipahami bahwa secara kronologis umat Islam diperintahkan untuk taat kepada Allah swt dalam arti mengerjakan semua yang diperintahNya dan berupaya meninggalkan apa-apa yang dilarangNya juga mentaatikepada utusan Allah swt, dalam arti segala apa yang diucapkan, diperbuat dan ditetapkan oleh Rosulullah maka wajib ditaati, sedangkan kewajiban taat kepada ulil amr yaitu pemerintah atau penguasa yang termasuk di dalamnya adalah ahl al-halli wa al-'aqd.

Bila Alqur'an dan sunnah sebagai dua sumber perundangundangan Islam tidak menyebutkan Ahlul Hilli wal Aqdi atau Dewan Perwakilan Rakyat, namun sebutan itu hanya ada didalam turats fiqih kita di bidang politik keagamaan dan pengambilan hukum substansial dari dasar-dasar menyeluruh, maka dasar sebutan ini di dalam Alqur'an ada dalam mereka yang disebut dengan "ulil amri".

Adapun yang disebutkan dengan adanya dasar Ahlul Hilli wal Aqdi dalam kitab Allah, yakni ulil amri legislatif dan pengawasan atas kewenangan eksekutif, terutama pimpinan tertinggi negara, ia hanya disebutkan dengan lafal Al-Ummah, dan tugasnya hanya terbatas pada dua hal. Pertama, mengajak kepada kebaikan, termasuk di dalamnya segala perkara umum yang di antaranya menetapkan hukum atau peraturan untuk rakyat yang dibuat lewat musyawarah. Kedua, menindak para penguasa yang zalim, yakni yang melakukan penyimpangan dalam pemerintahan. 
228 | TAZKIR: Jurnal Penelitian Ilmu-ilmu Sosial dan Keislaman

Vol. 03 No. 2 Desember 2017

Perputaran zaman ini mengundang para ahli hukum Islam untuk memberikan pembagian kekuasaan negara, karena situasi dan kondisi menghendakinya, sehingga mereka membagi kekuasaan negara itu kepada beberapa bagian sesuai dengan kebutuhan. Adanya pembagian kekuasaan di zaman para sahabat itu tidak jauh dengan konsepan Negara Indonesia, di Indonesia sendiri terbagi 3 lembaga yaitu; (1) lembaga eksekutif (2) lembaga yudikatif (3) lembaga legislatif di antara lembagalembaga ini mempunyai fungsi dan wewenang masing-masing yang diatur oleh undang-undang dasar 1945.

DewanPerwakilan Daerah (DPD) Lahirpadatanggal 1 Oktober 2004, ketika 128 anggota DPD yang terpilih untuk pertama kalinya dilantik dan diambil sumpahnya. Pada awal pembentukannya, masih banyak tantangan yang di hadapi oleh DPD. Tantangan tersebut mulai dari wewenangnya yang dianggap jauh dari memadai untuk menjadi kamar yang kedua yang efektif dalam sebuah parlemen bicameral, sampai dengan persoalan kelembagaannya yang juga jauh dari memadai, tantangan-tantangan tersebut timbul terutama karena tidak banyak dukungan politik yang diberikan kepada lembaga baru ini.

Selain itu takkala UUD NRI Tahun 1945 diganti dengan konstitusi RIS pada 27 Desember 1949 sebagai konsekuensi terjadinya perubahan bentuk dari negara kesatuan menjadi negara federal, didalam konstitusi RIS diatur keberadaan lembaga negara senat yang masuk dalam ranah kekuasaan legislatif (walaupun terbatas) dan berfungsi pula sebagai majelis penasehat sebagai majelis penasehat bagi pemerintah.

Konstitusi RIS diganti dengan UUD 1950. Di dalam konstitusi ini tidak diatur mengenai lembaga negara semacam DPD. Perubahan UUD NRI Tahun 1945 yang dilakukan MPR pada awal era reformasi berhasil membentuk lembaga negara Dewan Perwakilan Daerah (DPD) yang diatur dalam pasal 22C dan pasal 22D UUD NRI Tahun 1945.

DPD dibentuk sebagai hasil perubahan ketiga UUD 1945 yang disahkan MPR pada 9 november 2001. Dengan kehadiran DPD tersebut maka dalam sistem perwakilan Indonesia, DPR didukung dan diperkuat oleh DPD. Apabila DPR merupakan lembaga perwakilan berdasarkan aspirasi daerah/wilayah. Keberadaan DPD memang sangat terkait dengan daerah dan di pandang sebagai lembaga perwakilan yang saling 
melengkapi dengan DPR. Anggota DPD dipilih dari setiap provinsi melalui pemilihan umum dan jumlahnya dari setiap provinsi sama dan jumlah anggota DPR. Untuk pertama kalinya, kursi DPD di isi para anggotanya sebagai hasil pemilu 2004 dimana para pemilih memilih 128 anggota DPD.

Sesuai UU susunan dan kedudukan MPR, DPR, DPD, dan DPRD, jumlah anggota DPD sebanyak empat orang untuk tiap-tiap provinsi. Mengingat pada saat pemilu 2004 tersebut jumlah provinsi sebanyak 32 provinsi, dalam perkembangannya jumlah anggota DPD bertambah menjadi 132 orang sebagai hasil pemilu 2009 mengingat terdapat penambahan satu provinsi (menjadi 33 provinsi).

Permasalahan DPD menjadi isu paling strategis yang di bahas panjang lebar dalam pembahasan materi ini di PAH 1 BP MPR di karenakan hal itu akan menentukan kekuatan DPD, terutama apa bila di sandangkan dengan DPR yang sama-sama masuk rumpun kekuatan legislatif. Berdasarkan dari sekilas latar belakang tersebut di atas maka penulis tertarik untuk melakukan penelitian mengenai kedudukan DPD RI dalam sistem tata negara Indonesia dilihat dari perspektif sistem tata negara Islam.

\section{RUMUSAN MASALAH}

Rumusan masalah dari penelitian ini adalah bagaimana kedudukan DPD RI dalam sistem tata negara Indonesia dan bagaimana kedudukan DPD RI dalam tata negara menurut perspektif siyasah.

\section{TUJUAN PENELITIAN}

Berdasarkan rumusan masalah yang dikemukakan diatas adalah

1. Untuk mengetahui kedudukan DPD dalam sistem tata negara Indonesia.

2. Untuk mengetahui bagaimana perspektif siyasah terhadap kedudukan DPD RI dalam sistem tata negara Indonesia.

\section{METODE PENELITIAN}

Jenis penelitian ini termasuk penelitian pustaka ( libray reseach) yaitu serangkaian penelitian yang berkenaan dengan metode 
230 | TAZKIR: Jurnal Penelitian Ilmu-ilmu Sosial dan Keislaman

Vol. 03 No. 2 Desember 2017

pengumpulan data pustaka atau penelitian yang objek penelitiannya digali melalui beragam informasi kepustakaan (buku, insoklopedia, jurnal ilmiah, Koran, majalah dan dokumen).

Sumber data primer yaitu bahan hukum yang digunakan adalah literature atau data-data yang langsung dikumpulkan atau diperoleh dari sumber pertamanya, yang berkaitan dengan masalah tersebut sebagai acuan pokok dalam penelitian ini adalah Fikih Siyasah, Fikih Politik Islam, Ahkam as-Sulthaniyah.

Sumber data sekunder merupakan sumber data yang diperoleh melalui pihak lain yang menulis tentang DPD atau ahl-hall wa al-aqd tetapi yang mendukung pembahasan ini.

Selain dari sumber data sekunder juga menggunakan al-Qur'an dan Hadits.

Sumber data tersier merupakan data yang member petunjuk dan penjelasan terhadap sumber data primer dan sumber data sekunder seperti kamus-kamus dan ensiklopedia.

\section{METODE PENDEKATAN}

Pendekatan yang digunakan dalam penelitian ini adalah pendekatan perundang-undangan (Statute Approach). Pendekatan ini dilakukan dengan menelaah perundang-undangan yang bersangkut paut dengan permasalahan (isu hukum) yang sedang dihadapi.

Pendekatan Konseptual (Conceptual Approach) beranjak dari pandangan-pandangan di dalam ilmu hukum. Pendekatan ini menjadi penting sebab pemahaman terhadap pandangan/ doktrin yang berkembang dalam ilmu hukum dapat menjadi pijakan untuk membangun argumentasi hukum ketika menyelesaikan isu hukum yang dihadapi. Pandangan/ doktrin akan memperjelas ide-ide dengan memberikan pengertian-pengertian hukum, konsep hukum, maupun asas hukum yang relevan dengan permasalahan.

Teknik pengumpulan bahan hukum sesuai dengan pendekatan yang dilakukan. Peneliti mencari dan menggali bahan-bahan pustaka yang searah dengan objek pembahasan sehingga dilakukan pemeriksaan bahan hukum, mengklarifikasi, menguji, menganalisis bahan-bahan hukum tersebut baik primer maupun sekunder secara normatif dan 
yuridis formil dengan alasan alasan penulis untuk saling dibandingkan dalam rangka mendapatkan suatu kesimpulan.

\section{HASIL PENELITIAN}

Kedudukan lembaga Dewan Perwakilan Daerah Republik Indonesia (DPD RI) dalam sistem ketatanegaraan Indonesia setara dengan lembaga lainnya baik itu dari lembaga eksekutif, legislatif, dan yudikatif, maka sudah menjadi suatu keharusan bahwa lembaga-lembaga negara harus menjadikan konstitusi sebagai pedoman mereka dalam menjalankan tugas pokok dan fungsinya masing-masing. Meskipun DPD berhak mengajukan rancangan undang-undang namun hanya pada tingkat pertama saja, sedangkan pembahasan lebih lanjut dilakukan oleh DPR .

Pandangan siyasah terhadap kedudukan DPD RI dalam sistem ketatanegaraan Islam secara spesifik disebut dengan Ahlu al-Halliwa alAqdi lembaga tersebut mempunyai kedudukan yang lebih luas, dalam pemerintahan Islam antara khalifah dan Ahlu al-Halli wa al-Aqdi bekerja sama dalam menyelenggarakan pemerintahan yang baik demi kemaslahatan umat. Kedudukan Ahlu al-Halli wa al-Aqdi dalam pemerintahan adalah sebagai wakil rakyat yang salah satu tugasnya adalah memilih khalifah dan mengawal khalifah menuju kemaslahatan umat. Jadi kedudukan Ahlu al-Halli wa al-Aqdi dalam pemerintahan adalah sebuah lembaga yang mempunyai tugas wewenang sendiri tanpa intervensi khalifah. Persamaan tugas DPD RI dengan Ahlu al-Halli wa alAqdi adalah perwakilan daerah, membuat rancangan undang-undang atau aturan hukum untuk kemaslahatan masyarakat, adapun perbedaannya antara DPD RI dengan Ahlu al-Halli wa al-Aqdi adalah memberi usulan atas rancangan undang-undang. Sedangkan Ahlu al-Halli wa al-Aqdi mempunyai kewenangan tak terbatas dalam rancangan undang-undang, DPD RI merupakan lembaga yang mempunyai kedudukan kewenangan yang hanya bisa mengusulkan suatu rancangan undang-undang, sedangkan Ahlu al-Halliwa al-Aqdi merupakan perwakilan rakyat yang dapat memberi fatwa. 
232 | TAZKIR: Jurnal Penelitian Ilmu-ilmu Sosial dan Keislaman

Vol. 03 No. 2 Desember 2017

\section{KESIMPULAN}

Berdasarkan uraian yang telah di paparkan diatas sebelumnya maka dapat disimpulkan sebagai berikut:

Kedudukan lembaga Dewan Perwakilan Daerah Republik Indonesia (DPD RI) dalam sistem ketatanegaraan Indonesia setara dengan lembaga lainnya baik itu dari lembaga eksekutif, legislatif, dan yudikatif, maka sudah menjadi suatu keharusan bahwa lembaga-lembaga negara harus menjadikan konstitusi sebagai pedoman mereka dalam menjalankan tugas pokok dan fungsinya masing-masing. Meskipun DPD berhak mengajukan rancangan undang-undang namun hanya pada tingkat pertama saja, sedangkan pembahasan lebih lanjut dilakukan oleh DPR .

Pandangan siyasah terhadap kedudukan DPD RI dalam sistem ketatanegaraan Islam secara spesifik disebut dengan Ahlu al-Halliwa al-Aqdi lembaga tersebut mempunyai kedudukan yang lebih luas, dalam pemerintahan Islam antara khalifah dan Ahlu al-Halli wa al-Aqdi bekerja sama dalam menyelenggarakan pemerintahan yang baik demi kemaslahatan umat. Kedudukan Ahlu al-Halli wa al-Aqdi dalam pemerintahan adalah sebagai wakil rakyat yang salah satu tugasnya adalah memilih khalifah dan mengawal khalifah menuju kemaslahatan umat. Jadi kedudukan Ahlu al-Halli wa al-Aqdi dalam pemerintahan adalah sebuah lembaga yang mempunyai tugas wewenang sendiri tanpa intervensi khalifah. Persamaan tugas DPD RI dengan Ahlu al-Halli wa al-Aqdi adalah perwakilan daerah, membuat rancangan undang-undang atau aturan hukum untuk kemaslahatan masyarakat, adapun perbedaannya antara DPD RI dengan Ahlu alHalli wa al-Aqdi adalah memberi usulan atas rancangan undang-undang. Sedangkan Ahlu al-Halli wa al-Aqdi mempunyai kewenangan tak terbatas dalam rancangan undang-undang, DPD RI merupakan lembaga yang mempunyai kedudukan kewenangan yang hanya bisa mengusulkan suatu rancangan undangundang, sedangkan Ahlu al-Halliwa al-Aqdi merupakan perwakilan rakyat yang dapat memberi fatwa. 


\section{DAFTAR PUSTAKA}

Abdul Khaliq, Farid, Fikih Politik Islam, Jakarta 13220: Sinar Grafika Offset, 2005.

Akbar, Patrialis, Lembaga-Lembaga Negara Menurut UUD NRI Tahun 1945, Jakarta: Sinar Grafika, 2013.

Alvian Nasution, Kaka, Buku lengakap Lembaga- Lermbaga Negara, Jakarta Selatan: Serambi Semesta Distribusi, 2014.

Ibrahim, Johnny, Teori dan Metodologi Penelitian Hukum Normatif, Malang: UMM Press, 2007

Iqbal, Muhammad, Fiqih Siyasah kontekstualisasi Doktrin Politik Islam, Jakarta: Radar Jaya Pratama Jakarta Anggota IKAPI, 2001.

Kamal Fakih, Allamah dan tim ulama, Tafsir Nurul Qur'an, Jakarta: AlHuda. Shafar 1425/ April 2004.

Pieris, John dan Aryanti Baramuli Putri, Dewan Perwakilan Daerah Republik Indonesia, Yogyakarta: Graha Ilmu, 2010.

Mahmud, Metode penelitian Pendidikan, Bandung: pustaka setia, 2011.

Nata, Abuddin, Masail Al-Fiqhiyah, Jakarta Timur: Prenada Media, 2003

Rahman Sholeh, Abdul, Pendidikan Agama dan Pengembangan untuk Bangsa, Jakarta: PT. Raja Grafindo Persada, 2005.

Rahardjo, Dawan, Ensiklopedia Al-Qur'an: Tafsir Sosial Berdasarkan KonsepKonsep Kunci, Jakarta:Paramadina, 2002.

Sugiyono, Metode Penelitian Kuantitatif, Kualitatif, dan $R \mathcal{E} D$, Bandung: Alfabeta, 2007.

Syafe'I, Zakaria, Negara Dalam Persfektif Islam Fiqih Siyasah, Jakarta: Hartono Media Pustaka, 2012.

Thoha, Ahmadie, Muqaddimah ibn Khaldun, Jakarta: Pustaka Firdaus, 2005.

Yusuf,M. Dewan Perwakilan Daerah Republik Indonesia, Yogyakarta: Graha Ilmu, 2009. 
234 | TAZKIR: Jurnal Penelitian Ilmu-ilmu Sosial dan Keislaman

Vol. 03 No. 2 Desember 2017

Wahhab khallaf Abd al, al-Siyasah al-Syar'iyyah aw Nizham al-Dawlah al Islamiyyah fi Syu'un al-Dusturiyyah wa al-Kharijiyyah wa al-Maliyyah, al-Qahirah: Mathba' ah al-Taqaddum, 1397H/1977M.

Suasadi, Metode penelitian, lampung : Pusat Penelitian dan Penerbitan LP2M Institut Agama Islam Negeri Raden Intan Lampung, 2015.

Undang-undang Republik Indonesia No 32 tahun 2004 Tentang Pemerintahan Daerah, Pasal 18

Undang-undang dasar negara Republik Indonesia tahun 1945, Perubahan ketiga, Jakarta: Sekretariat Jenderal MPR RI, 2015 